Laboratoire d'Economie de la Production et de I'Intégration Internationale

Département Energie et Politiques de

l'Environnement (EPE)

FRE 2664 CNRS-UPMF

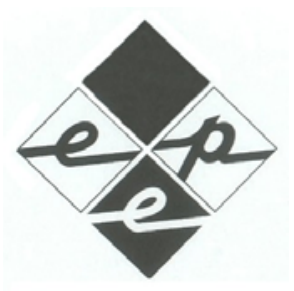

\title{
What factors influence mitigative capacity?
}

A paraître dans Energy Policy

Harald Winkler

Kevin Baumert

Odile Blanchard

Sarah Burch

John Robinson

janvier 2006 



\title{
What factors influence mitigative capacity?
}

\author{
Harald Winkler*, Kevin Baumert", Odile Blanchard^, Sarah Burch and John \\ Robinson ${ }^{+}$
}

* Corresponding author: Energy Research Centre, University of Cape Town, Private Bag, Rondebosch 7701 South Africa; harald@erc.uct.ac.za; Tel +27 21 650-2100; Fax +27 21 6502830.

\# World Resources Institute, Washington DC

$\wedge$ Laboratoire d'Economie de la Production et de l'Intégration Internationale- Energie et Politiques de l'Environnement, Grenoble

+ University of British Columbia, Vancouver

\begin{abstract}
:
This article builds on Yohe's seminal piece on mitigative capacity which elaborates 'determinants' of mitigative capacity, also reflected in the IPCC's third assessment report. We propose a revised definition, where mitigative capacity is a country's ability to reduce anthropogenic greenhouse gas emissions or enhance natural sinks. By "ability" we mean skills, competencies, fitness, and proficiencies that a country has attained which can contribute to GHG emissions mitigation. A conceptual framework is proposed, linking mitigative capacity to a country's sustainable development path, and grouping the factors influencing mitigative capacity into three main sets: economic factors, institutional ones, and technology. Both quantitative and qualitative analysis of factors is presented, showing how these factors vary across countries. We suggest that it is the interplay between the three economic factors - income, abatement cost and opportunity cost - that shape mitigative capacity. We find that income is an important economic factor influencing mitigative capacity, while abatement cost is important in turning mitigative capacity into actual mitigation. Technology is a critical mitigative capacity, including the ability to absorb existing climate friendly technologies or to develop innovative ones. Institutional factors that promote mitigative capacity include the effectiveness of government regulation, clear market rules, a skilled work force and public awareness. We briefly investigate such as high abatement cost or lack of political willingness, that prevent mitigative capacity from being translated into mitigation.
\end{abstract}

\section{Résumé}

Cet article s'intéresse aux déterminants de la capacité à atténuer le changement climatique. Ceux-ci ont été élaborés initialement dans un papier de Yohe puis dans le troisième rapport d'évaluation du GIEC. Après avoir revisité la définition de la capacité à atténuer le changement climatique, nous identifions trois groupes de facteurs influençant de façon croisée cette capacité : des facteurs économiques, technologiques et institutionnels. Au niveau économique, ce sont à la fois le revenu, le coût de réduction des émissions et le coût d'opportunité lié aux réductions qui forgent la capacité d'atténuation. Du côté technologique, c'est la capacité à absorber ou à développer des technologies peu émettrices de gaz à effet de serre qui est déterminante. Enfin, au niveau institutionnel, l'efficacité de la régulation gouvernementale, la transparence des règles de marché, une main d'œuvre qualifiée et une sensibilisation de la population sont des éléments clés. Notre analyse est menée à la fois qualitativement et quantitativement. Elle permet de montrer comment les facteurs influençant la capacité d'atténuation varient d'un pays à l'autre. 


\section{Introduction}

Climate change is one of the foremost challenges facing the global community. Since the beginning of the industrial revolution, atmospheric concentrations of carbon dioxide $\left(\mathrm{CO}_{2}\right)$, the chief heat-trapping greenhouse gas (GHG), have risen 35 percent. This increase is primarily due to the burning of fossil fuels and deforestation. If current emissions trends are not altered, global temperatures are expected to rise 1.4 to $5.8^{\circ} \mathrm{C}\left(2.5\right.$ to $\left.10.4^{\circ} \mathrm{F}\right)$ by 2100 , according to the Intergovernmental Panel on Climate Change (IPCC 2001a). The effects of such temperature changes on agricultural production, water supply, forests, and overall human development are not fully known, but are likely to be detrimental to a large portion of the world's population, particularly in developing countries.

The 1992 UN Framework Convention on Climate Change establishes the ultimate objective of stabilizing atmospheric concentrations of GHGs at a level that avoids dangerous human interference with the climate system. The Convention also establishes guidance regarding the relative degree of effort expected by Parties. Namely, while all Parties should take GHG mitigation actions, they should do so on the basis of equity and their "common but differentiated responsibilities and respective capabilities" (UNFCCC 1992). Further, Parties have a "right" to sustainable development, and the "[p]olicies and measures to protect the climate system ... should be ... integrated with national development programmes" (Article 3.4). Thus, the basic framework agreed to by all Parties is that countries should undertake GHG mitigation on the basis of their relative responsibility for the problem and capability to take actions, within the broader context of promoting sustainable development.

The concept of "responsibility" is well known and has been examined widely. The industrialized countries, home to about $20 \%$ of the world's population, have contributed approximately $75 \%$ of the total of $\mathrm{CO}_{2}$ emissions from energy sources since 1850 . Since 1950 , if $\mathrm{CO}_{2}$ from deforestation is also included in the calculation, this figure shifts to just over $50 \%$ (WRI 2003). At the same time, it is clear that annual emissions of developing countries are growing rapidly, and will need to be slowed in order to promote sustainable development.

On the other hand, the concept of "capability" to mitigate climate change is not well understood in the climate policy community, and has been less frequently examined in the literature. This paper explores the concept of mitigative capacity, and seeks to advance the existing literature on this topic in several ways.

The concept of mitigative capacity needs to be understood within the broader context of promoting sustainable development, a consideration that will remain essential for both the developed and developing world (Winkler et al. 2002; Munasinghe \& Swart 2005; Shukla et al. 2002; Davidson 2002; Gupta \& Bhandari 1999; Pan 2002; Heller \& Shukla 2003). The IPCC's work on emission scenarios shows that different future development pathways will have a very large influence on eventual emission levels. Accordingly, in achieving the Convention objective, development paths are at least as important as climate policy-a factor that should not be overlooked in the efforts to broaden the participation in emission-reduction efforts in the international climate regime (see overviews in Baumert et al. 2002; Bodansky et al. 2004; Höhne et al. 2004; Swart et al. 2003).

Mitigative capacity may provide an important link between development pathways and mitigation. While alternative development pathways lead to different levels of emissions, it is the capacity to change from one pathway to another-either through mitigation policy, but also through non-climate policy - that is important (Robinson et al. forthcoming). Understanding the factors that influence mitigative capacity may help illuminate how the shift of development paths might occur. A closer examination of the factors should make clear where capacities are applied to climate change specifically, and where broader development policies are more influential. 
First, we offer a simplified definition of mitigative capacity. Second, we offer a conceptual framework, with which the IPCC's Third Assessment Report (TAR) set of mitigative capacity determinants can readily align. This article also elaborates some of these determinants further. Third, in subsequent sections, we seek to provide quantitative analysis of some of the factors that shape mitigative capacity, suggesting that analysis of the data used in mitigation analysis will shed further light on mitigative capacity, including which countries have more of it, or less. Not all the factors that influence mitigative capacity are quantifiable, which poses inherent limits to this analysis. Nevertheless, our view is that a quantitative analysis could deepen understanding of mitigative capacity. Indeed, the TAR noted that "[d]eveloping indicators of mitigative capacity could help determine who should be expected to do what in terms of mitigation".(IPCC 2001b: 107) Finally, we discuss how mitigative capacity may be turned into actual mitigation, emphasising the importance of distinguishing clearly between the two.

\section{Definitions and conceptual frameworks}

The IPCC Third Assessment Report defines a nation's mitigative capacity as reflecting “its ability to diminish the intensity of the natural (and other) stresses to which it might be exposed".(Banuri \& Weyant 2001: 103) Following on a seminal piece by Yohe (2001), the IPCC offers a listing of "determinants" of mitigative capacity:

1. range of viable technological options for reducing emissions;

2. range of viable policy instruments with which the country might effect the adoption of these options;

3. structure of critical institutions and the derivative allocation of decision-making authority;

4. availability and distribution of resources required to underwrite their adoption and the associated, broadly defined opportunity cost of devoting those resources to mitigation;

5. stock of human capital, including education and personal security;

6. stock of social capital, including the definition of property rights;

7. country's access to risk-spreading processes (e.g., insurance, options and futures markets, etc.); and

8. ability of decision makers to manage information, the processes by which these decision makers determine which information is credible, and the credibility of the decision makers themselves.

The IPCC, citing Yohe (2001), framed mitigative capacity as related to technology, policy options and resources, but also "upon nation-specific characteristics that facilitate the pursuit of sustainable development - e.g., the distribution of resources, the relative empowerment of various segments of the population, the credibility of empowered decision makers, the degree to which climate objectives complement other objectives, access to credible information and analyses, the will to act on that information, the ability to spread risk intra- and intergenerationally, and so on" (IPCC 2001b: 21). ${ }^{1}$ This view of mitigative capacity is explicitly presented as the "mirror image" of adaptive capacity, which is considerably developed in the IPCC TAR on impacts, vulnerability and adaptation.(IPCC 2001c).

We define mitigative capacity simply as a country's ability to reduce anthropogenic greenhouse gas emissions or enhance natural sinks. By "ability" we mean skills, competencies, fitness, and proficiencies that a country has attained which can contribute to GHG emissions mitigation.

\footnotetext{
${ }^{1}$ Section 1.3 of the Technical Summary of WGIII contribution to the Third Assessment Report, p. 21
} 
This definition differs somewhat from the TAR definition which, as noted, conceptually "mirrors" the definition of adaptive capacity. Under the TAR formulation, adaptive capacity deals with reducing exposure or sensitivity to stresses (e.g., climatic events), whereas mitigative capacity speaks to reducing the intensity of the stress itself. Yet, as a practical matter, under this formulation, only large (i.e. high emissions) countries could have mitigative capacity. Small countries have no ability to reduce the stress of climate change on them; that is, no amount of capacity that they have, from a climate change mitigation point of view (unlike an adaptation point of view), will reduce the stress of climate change. Rather, it will be the mitigation activities (or lack thereof) undertaken by the rest of the world that will determine the level of climatic change. By emphasizing stresses, the TAR definition of mitigative capacity lessens the focus on GHG emissions, the build-up of which is the direct cause of anthropogenic climate change. Furthermore, the emphasis on natural stresses (with 'other' in brackets) seems inappropriate for mitigation, which focuses on reducing anthropogenic emissions. Accordingly, the simple definition we adopt focuses directly on GHG emissions.

We acknowledge that in important ways the factors influencing adaptive and mitigative capacity are overlapping and mutually supportive. Certainly adaptive and mitigative capacities are rooted in the same substrate - the development path of a country - but they differ in application. The same capacity may be applied either to respond to the impacts of climate change, or to reduce greenhouse gas (GHG) emissions. As mitigative capacity is translated into actual mitigation (see section 6), the capacity becomes more concrete and specific. The definition adopted here recognizes some inherent differences between the application of adaptive and mitigative capacity. For example, applying an increased adaptive capacity reduces the vulnerability at a community or local level within a country. The use of mitigative capacity (i.e. actual mitigation), by contrast, reduces the intensity of climate change at a global scale by slowing the atmospheric build-up of greenhouse gases. The benefits (or even costs) that this reaps for a particular community or country are relatively indirect, a key fact which makes climate change mitigation so immensely challenging. Because mitigative capacity is a complex issue, and our definition is simple, some initial elaboration is required.

First, we need to clarify that mitigative capacity is the ability to reduce GHG emissions in either absolute or relative terms. Absolute reductions would be analogous to most targets under the Kyoto Protocol, where most Annex I Parties are required to reduce their emissions below 1990 levels.(UNFCCC 1997) Relative emission reductions, in contrast, would reduce GHG emissions against a rising business-as-usual projection, but absolute emissions $\left(\mathrm{t} \mathrm{CO}_{2} /\right.$ year) may still rise. For developing countries that have never reached high levels of emissions, relative reductions can also be called 'avoided emissions'. In other words, absolute emissions could continue to rise, but at a slower pace (unless the intensity improvement was very stringent).

Second, mitigative capacity is not intended to simply explain the degree to which countries do in fact mitigate GHGs. It is about how much countries could mitigate - the ability to reduce emissions. If we compare mitigation to climbing a wall, then our ability to do so would depend on how strong, healthy and well-equipped we are, but also on characteristics of the wall itself (e.g. height, material it is made of, etc.). Does mitigative capacity refer only to our capabilities for climbing or to the combination of those capabilities and the characteristics of the wall? The focus of this paper is on capacity and the factors influencing it, in other words capability. However, capacity remains an abstraction without considering how it is translated into practical action. The translation of capacity into actual mitigation matters - the combination of climbing capabilities and wall in our analogy. What is less clear is whether it determines the capacity in turn. We briefly open this discussion in section 6, which is particularly relevant to understanding why countries fail to exercise their mitigative capacity. More work is needed on the translation of mitigative capacity into actual mitigation and the barriers to mitigation. 
Third, the basis of mitigative capacity in alternative development paths establishes a conceptual link between climate and sustainable development (non-climate) policies. Reducing emissions where they are already high - requires capacity. Mitigation should be carried out in a way that allows economic development to proceed in a sustainable manner, i.e. mitigation should not threaten a country's sustainable development (UNFCCC 1992: Article 2). Equally, however, following a more sustainable development path would avoid emissions, a fact of particular relevance for countries starting from relatively low emissions levels. Such countries would not need to get dirty first, to clean up later, thereby clearly contributing to the global mitigation effort. The capacity to choose an alternative development path is also mitigative capacity, in so far as that path has relatively lower emissions, and it is clearly related to sustainable development (Swart et al. 2003).

Fourth, we consider the extent to which mitigative and adaptive capacity are distinct, and the level at which they could be considered as part of a broader response capacity (Burch \& Robinson 2005). Response capacity is a very generalised form of ability to do something, not limited to any specific use. A well-educated work-force, for example, is capable in several different ways. At that general level, capacuities are linked - they are all rooted in the same development path. Once that generalized capacity is made concrete in terms of policies or institutional mandates for either mitigation or adaptation, it becomes more specific. Agencies or policies created to implement or support low-carbon energy systems (a form of mitigative capacity), for example, are different from those needed for development of resilient water systems (adaptive capacity).

Finally, as the IPCC has illustrated through its eight "determinants", mitigative capacity has multiple dimensions that are overlapping and interrelated. In attempts to clarify these dimensions, we offer a conceptual framework for mitigative capacity consisting of three main factors: economic factors, institutional ones, and technology. These three sets of factors are types of 'ability' in our definition of mitigative capacity. The factors are elaborated in the subsequent three sections and include multiple sub-factors and dimensions, some of which are not yet fully explored here. The sets of factors cannot be entirely separated, but indeed there are important interactions between them. The IPCC determinants of mitigative capacity can be mapped to these three broad factors (and sub-factors). However, we adopt the term "factor" in lieu of "determinant" because the latter suggests that each single item is decisive-if it is not present, there is no mitigative capacity. We prefer to call them factors, which in different combinations and weights collectively determine mitigative capacity. As the IPCC noted, there may be cases where a single factor has such great weight for a particular country that it is indeed decisive, but in other cases deficiencies in one factor may be compensated by other factors. This applies to economic factors as much as any other set.

\section{Economic factors}

The fourth 'determinant' of mitigative capacity in the TAR is the "availability and distribution of resources required to underwrite their adoption and the associated, broadly defined opportunity cost of devoting those resources to mitigation" (IPCC 2001b; Yohe 2001). Economic capacity is more central to the ability to reduce GHG emissions than the cryptic reference to availability of resources may suggest. The factors considered in this section are the ability to pay (related to income), abatement cost (the cost to mitigate) and opportunity cost (the foregone alternative use of money that would have been spent on mitigation).

\subsection{Ability to pay}

A country's income, measured by GDP per capita, is a first rough approximation of the availability of financial resources - although the complex issues of distribution and opportunity cost deserve further attention. Ability to pay, measured by GDP per capita, is an important factor in mitigative capacity - more wealth gives countries greater capacity to reduce emissions. 
Figure 1: Total and per capita income for selected countries and regions, 2000

Data source: CAIT (WRI 2003)

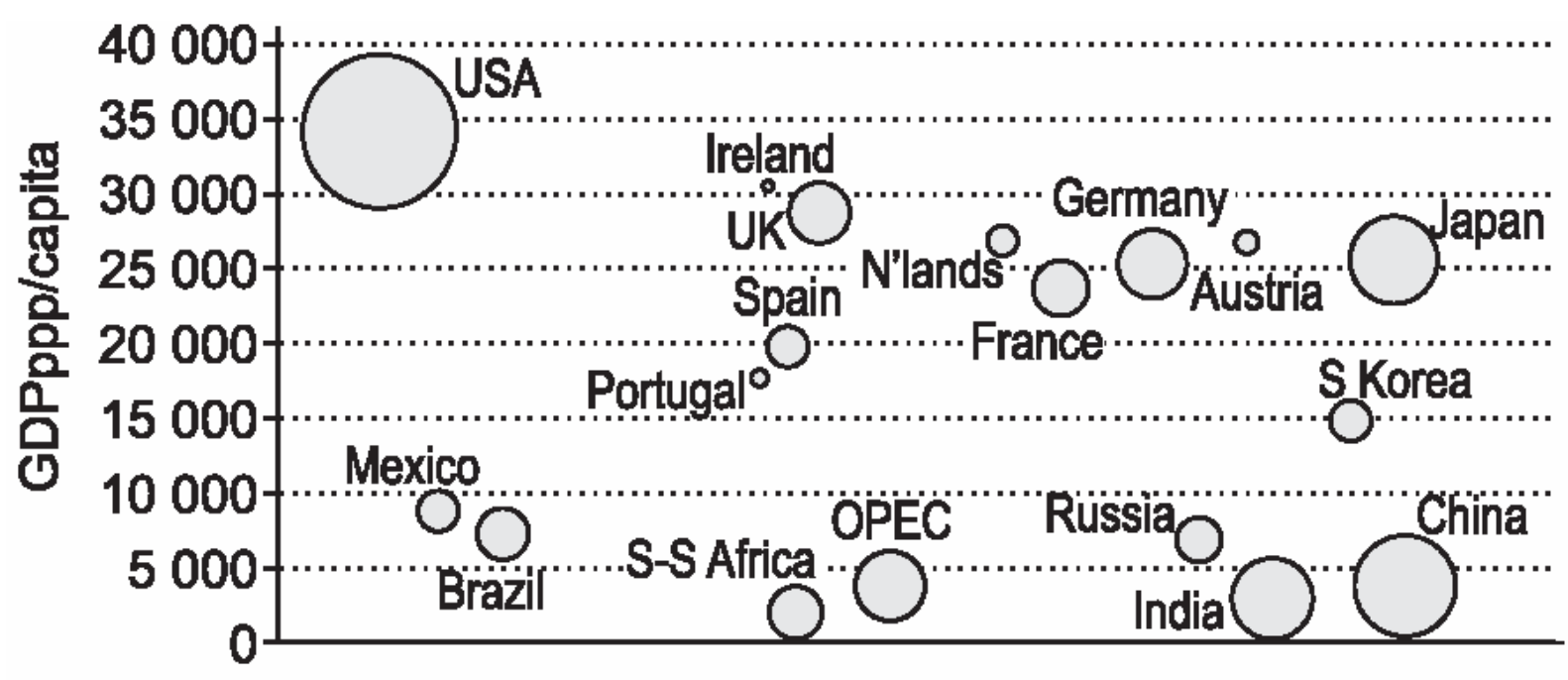

Dot size shows total GDP

Figure 1 shows selected regions grouped by per capita income on the y-axis, with the size of the dot showing total size of the economy as measured by GDP. Mitigative capacity may depend on per capita income in the first instance, but the absolute size of the economy also influences the extent to which a country can reduce emissions. In general, the higher GDP per capita and absolute size of the economy, the higher the ability to turn mitigative capacity into high levels of actual mitigation.

Analysis of ability to pay in isolation is limited. Income needs to be related to the expenditure required.

\subsection{Abatement cost}

How might abatement cost relate to ability to pay, and the two factors together shape mitigative capacity? One would probably think of income as the capacity per se, but how effectively this capacity can be applied depends on costs. Abatement cost is an important factor that can act as a barrier in turning mitigative capacity into actual mitigation.

We examine some data on average abatement costs and ability to pay to investigate this question. We relate ability to pay (using GDPppp per capita as a proxy ) to expenditure on mitigation.

Economic analysis of mitigation cost often focuses on marginal costs (Halsnaes et al. 1998; Hourcade \& Robinson 1996) or total costs as a share of GDP (Azar \& Schneider 2002; Nordhaus 1993). As the marginal cost reflects the cost of the last GHG ton abated, it does not provide information on the overall burden that a certain volume of emissions reductions may represent for the economy. Total cost as a share of GDP may show the effort rate imposed by mitigation on the economy. Average costs of achieving a certain level of mitigation allow for comparison of the cost per ton abated across countries. We have chosen to focus on the latter for our present purpose. 
The data below stems from the POLES model ${ }^{2}$ under the assumption that all countries reduce their $\mathrm{CO}_{2}$ emissions by $20 \%$ relative to their reference emissions in 2030. Under this assumption, 2030 world emissions are $71 \%$ higher than in 1990. All developing countries show emission levels greater than in 1990 while part of the industrialized countries show emission levels slightly below 1990 levels. Given these assumptions, average abatement costs are plotted against income per capita for year 2030 in Figure $2 .^{3}$

Figure 2: Per capita income plotted against average abatement cost for selected countries ${ }^{4}$

Data source: POLES model

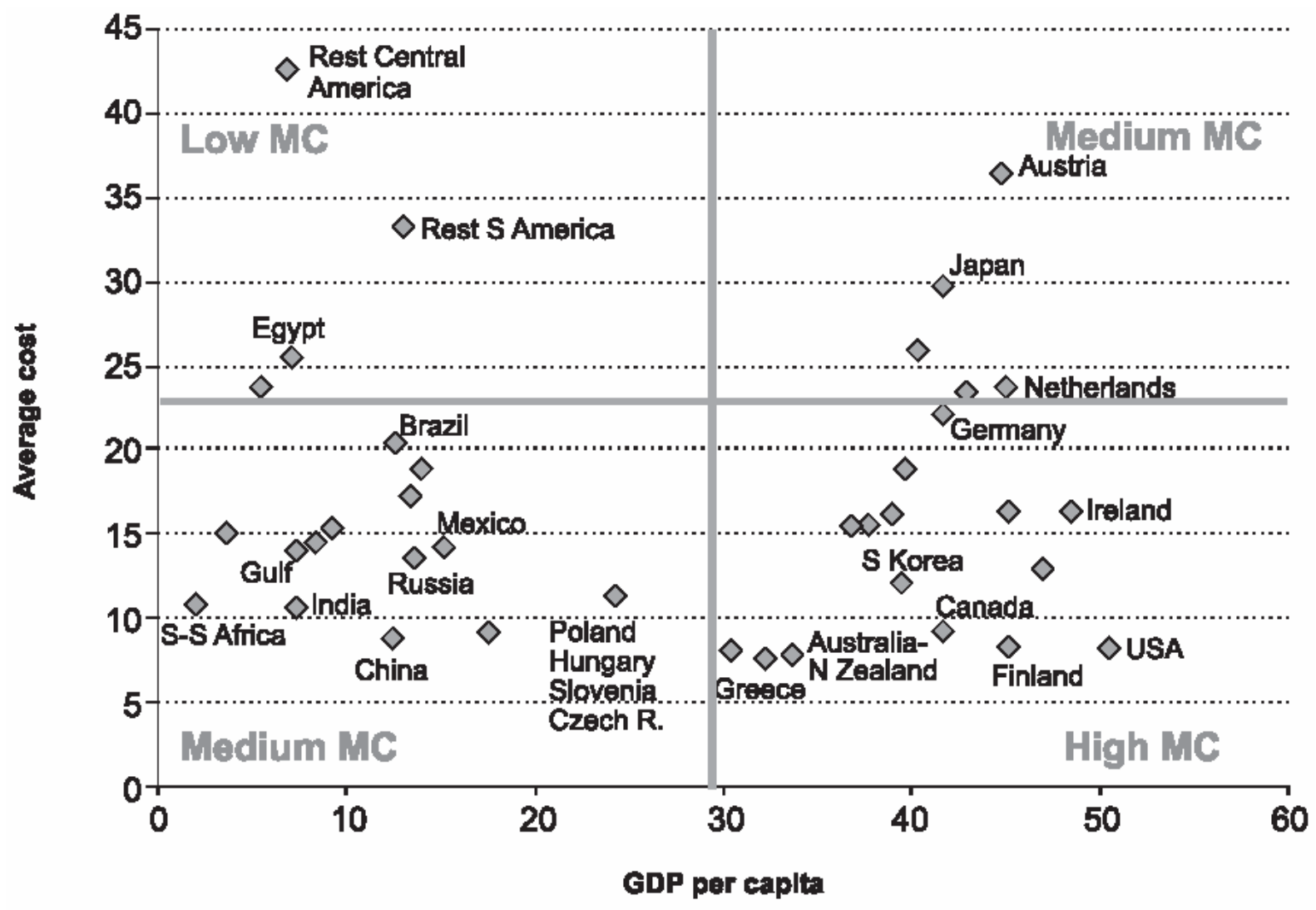

Note: Linear regression $\mathrm{R}^{2}=0.002$

Figure 2 confirms that the abatement costs are not linearly correlated to the level of income. Examining the four quadrants, some lessons for mitigative capacity can be drawn.

\footnotetext{
${ }^{2}$ POLES is a world simulation model for the energy sector (European Commission, 1996). It works in a year-by-year recursive simulation and partial equilibrium framework, with endogenous international energy prices and lagged adjustments of supply and demand by world region. GDP and population are the main exogenous variables. The world is divided into 38 countries or regions. For each country or region, the model articulates the following modules: final energy demand by key sectors, new and renewable energy technologies, conventional energy and electricity transformation system, fossil fuel supply. The main outputs comprise detailed world energy outlooks, marginal greenhouse gas emission abatement costs, and technology improvement scenarios.

${ }^{3}$ Costs are expressed in 1995 \$ while GDP per capita are in 1995 \$ PPP.

${ }^{4}$ Each plot on the figure is associated with a POLES' region or country. But the names are not all posted so as to get a clear view.
} 
The bottom-right quadrant contains countries with relatively high ability to pay and low average abatement costs. These countries clearly have high mitigative capacity (income) and are also able to translate this into actual mitigation due to low costs. The USA, Finland, Canada, South Korea, and Australia-New Zealand are examples among the set of countries shown here.

In the opposite quadrant (top-left), mitigative capacity is conversely low. In this example, South American countries excluding Brazil, Central American countries excluding Mexico, Egypt show low abilities to pay. Their relatively high average abatement costs means that this capacity can be turned into even less actual mitigation.

The more complex cases arise in the remaining two quadrants. There is a group of poorer countries with low abatement cost curves in the bottom-left quadrant. Considering only average abatement cost, levels of actual mitigation might have been high; but in reality are not, since countries simply cannot afford to take advantage of low costs. China, India as well as Russia fall into this quadrant.

In the top-right quadrant, there is a group of high-income countries, which have relatively high mitigation costs. Mitigative capacity, as approximated by income, is equally high as in the bottom-right quadrant. However, higher costs mean that the ability to reduce emissions is not realised to the same extent. In some cases (e.g. Japan), this may be due to higher levels of efficiency in the economy already, so that additional improvements are more costly. Compared to the bottom-left quadrant, however, this group of countries still has higher mitigative capacity, simply by virtue of their higher ability to pay.

The conclusions drawn about countries or regions are illustrative. They are, of course, strongly determined by the model itself ${ }^{5}$ and by the mitigation scenario that we have assumed. Still, it is interesting to note that the conclusions are similar when assuming an emissions reduction rate of $40 \%$ or $60 \%$ relative to 2030 reference levels for all countries. Comparing the $-20 \%$ case (see Figure 2) with a $-60 \%$ case (not shown here), we found both Finland and the US to have high mitigative capacity, with high ability to pay. They also both have low abatement costs, indicating that they should be able to translate this capacity into actual mitigation. On their own, the economic factors clearly do not explain why the former acts under the Kyoto Protocol while the latter does not.

\subsection{Opportunity cost}

The issue of opportunity costs was raised in examining the situation of poorer countries with low average abatement costs (see the bottom-left quadrant in Figure 2). Opportunity cost is defined in economics as the best foregone alternative use of the money. Alternative demands on the budget are a crucial issue for developing countries, who have long argued that they need to develop and during this process cannot take on mitigation commitments. Opportunity costs are not simply economic considerations, but part of political economy. Low-income countries do not spend on mitigation even if they have low-cost mitigation opportunities, simply because they are spending their income on other things, for example development.

The trade-off between expenditure on mitigation and other goods can be represented graphically by a production possibility frontier (PPF), as in Figure 3. The assumption is that a country's economy produces mitigation and 'all other goods'. Scarce resources are not equally useful in all activities. The resources are traded directly, and prices do not enter the analysis.

The concave shape of the frontier implies an increasing opportunity cost of mitigation - for a small amount of mitigation and high amount of 'other goods', relatively little else is foregone per unit of mitigation, but as more mitigation is undertaken, relatively more 'other goods' are foregone (following Norgaard 1994; De Canio et al. 2000).

\footnotetext{
${ }^{5}$ Like marginal abatement costs, average abatement costs may differ widely from one model to the other for a given abatement scenario. Comparisons of marginal abatement costs across models and analysis of the discrepancies have been performed for example in (Weyant et al. , 1999; Blanchard et al., 2000)
} 
In many cases, 'other goods' might represent development, in as far as economic growth and emissions remain coupled. In some cases, however, development may be achieved in a more sustainable manner, e.g. providing access to electricity through renewables. The shape of the PPF (e.g. the solid line in Figure 3) is a key factor in mitigative capacity.

Figure 3: Expanding production possibility frontier for mitigation and other goods

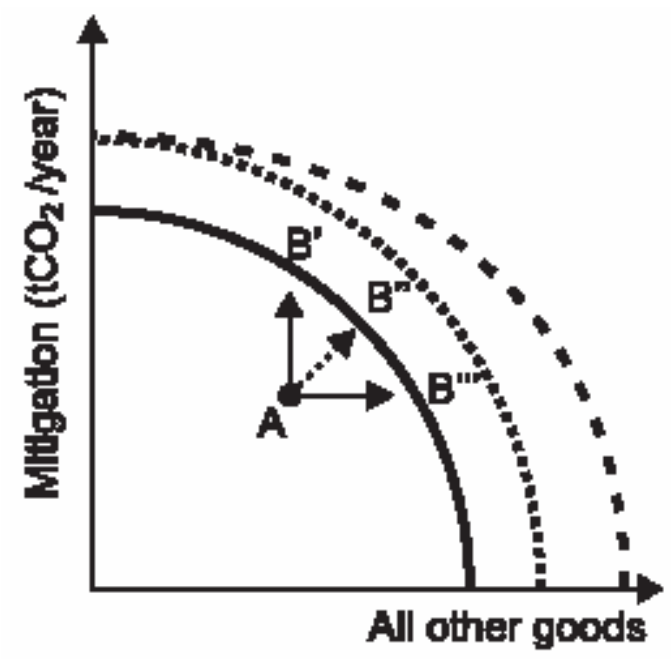

In Figure 3, the current situation of a given economy or sector may be at point A, i.e. not at the production possibility frontier. In this situation, the country or sector is not using its resources to their full extent. If this is the case, the economy can move from A to three different points on the PPF.

- Moving from A to B' increases mitigation, but does not add to other goods.

- Shifting to B" " by contrast only increases other goods, but does not reduce emissions.

- The move from A to B', is a vector that has both components, i.e. more 'other goods' are produced while also reducing emissions.

The three paths indicate different responses to the same opportunity costs, represented by the shape of the PPF curve.

If a country is already on the PPF, then its options are limited to shifts along the PPF. Unless, that is, it can expand the PPF to a new level, i.e. increase its overall capacity to mitigate and provide more 'other goods' to its people, as in the dotted lines in Figure 3. The PPF need not expand evenly in all directions, but could change unevenly as shown with the second dotted line below.

The reasons why the PPF might expand could include a rise in national income over time, a technological break-through that makes more mitigation available at lower cost, and related a lower cost per unit of mitigation (not shown explicitly in the PPF context). In other words, the expansion of the PPF represents an increase in capacity, rather than explains it. The cost factors considered above, together with the institutional factors and availability of resources, influence the shape of the PPF. If a country is able to shift its PPF to allow more mitigation while still developing other goods, its mitigative capacity is increased. 
The discussion of economic factors suggests that at least three factors combine to shape mitigative capacity. Ability to pay, as approximated by income, is an important capacity. However, how effectively that capacity can be converted into actual mitigation depends on the costs of abatement. Foregone expenditure on other goods, the opportunity cost, will further influence whether mitigative capacity is exercised - a country may have high mitigative capacity, but not use this capacity due to other demands on its budget. Figure 2 provided an example - for a hypothetical level of mitigation effort - of how the interrelationship between ability to pay and abatement cost varies across countries.

Economic factors, such as income and costs, do not exist in isolation, but in the context of institutions. Next, we turn to a set of institutional factors that influence mitigative capacity.

\section{Institutional factors}

A variety of institutional factors shape mitigative capacity. Key factors include the effectiveness of regulation in government and for markets, the skills base of a country, and levels of public awareness. Most of these factors are qualitative, although some quantitative data can help illustrate variation of capacity across countries.

\subsection{Regulatory effectiveness and market rules}

The ability of the government to formulate and implement sound policies shapes their ability to reduce GHG emissions. The capacity to monitor and enforce regulations will shape regulatory control over private entities. The effectiveness of the court system in enforcing contracts is a particular instance. If strong monitoring capacity exists in general, it is more likely that a government will be able to regulate private entities in achieving GHG emission reductions.

In developing countries, some initial experience with institutional capacity for mitigation has been gathered through the Clean Development Mechanism (CDM). Some developing countries have set up Designated National Authorities very rapidly, while others are not doing so at all. For poorer countries, it may make more sense to use existing institutional mechanisms, e.g. environmental impact assessments, to also deal with CDM projects (Winkler et al. 2005). The interaction appears to work in both directions - an expectation of potential mitigation projects motivates countries to set up institutions, but the presence of CDM offices in turn markets the country as a destination for climate investment. The initial lessons from the CDM provide some indication of potential government effectiveness in taking on quantified mitigation commitments. Higher regulatory effectiveness in government means higher mitigative capacity.

Effective rules for markets are another important factor. Clear market rules are needed to effectively apply economic mechanisms for mitigation. To impose a carbon tax, for example, assumes capacity of government not only to adopt the tax policy, but to effectively collect taxes from private entities. If there is no underlying competitive market for everyday goods and services, policy approaches such as taxes and trading may not live up to their theoretical potential. Participation in trading emissions requires legal institutions to ensure secure transactions and legal remedies. Existing markets for other goods would ensure that capital markets are in place and credit is available. Stronger markets imply a higher mitigative capacity.

\subsection{Education and skills base}

The skills base of a country is an important factor of mitigative capacity. Yohe's fifth determinant of mitigative capacity is the stock of human capital. In fact, basic education is essential for mitigation purposes, be it at the level of individuals, civil society, local communities, local authorities, national authorities or economic sectors. Education may raise public awareness of climate change, which may induce individual behavioural changes. It may also contribute to the building of expertise in climate change issues at the country level. 
Assessments such as GHG inventories or mitigation policies and strategies may be performed by national experts. These experts in turn advise policy makers. Basic education also plays a role in the deployment of mitigation technologies: it stands as a precondition for learning how to use available technologies, adapt them to the country's context and further develop a country's own set of mitigation technologies.

Table 1 shows the education index of selected countries as calculated in the Climate Analysis and Indicators Tool (CAIT) (WRI 2005), and the elementary components of the index.

Table 1: Education index, adult literacy rate, school enrolment ratio, 2001

Data source : CAIT (WRI 2005)

\begin{tabular}{l|c|c|c}
\hline \hline \multicolumn{1}{c|}{ Country } & Index & Adult Literacy rate & Enrolment Ratio \\
\hline (2/3 literacy rate, 1/3 & $\begin{array}{c}\text { (\% of people aged 15 } \\
\text { and above) }\end{array}$ & $\begin{array}{c}\text { (\% of population of school } \\
\text { age enrolled in education) }\end{array}$ \\
\hline United Kingdom & 100 & 99 & 100 \\
\hline United States of America & 97.6 & 99 & 94 \\
\hline Germany & 95.6 & 99 & 89 \\
\hline South Korea & 95.5 & 97.9 & 91 \\
\hline Japan & 93.2 & 99 & 83 \\
\hline Russian Federation & 92.8 & 99 & 82 \\
\hline Brazil & 88.5 & 87.3 & 95 \\
\hline Mexico & 83.5 & 91.4 & 74 \\
\hline South Africa & 80.4 & 85.6 & 78 \\
\hline China & 74.9 & 85.8 & 64 \\
\hline India & 49.2 & 58 & 56 \\
\hline \hline
\end{tabular}

A higher basic education level is a factor for higher mitigative capacity. This is the case for the industrialized countries and South Korea as shown in Table 1. Conversely developing countries such as Brazil, Mexico, China and India show relatively lower education indexes, which may contribute to lower mitigative capacity.

Still countries need more than basic education to absorb mitigation technologies and create newto-the world mitigation innovations ${ }^{6}$. Researchers are critical to mitigative capacity in this respect. The higher the number of researchers per million people is, the higher the mitigative capacity tends to be.

\footnotetext{
${ }^{6}$ Technological absorption is not only about learning but also adapting, upgrading existing technologies towards the creation of new technologies (Narula, 2004)
} 
Table 2: Number of researchers per million inhabitants for selected countries

Data source : UNESCO (2005)

\begin{tabular}{l|c|c}
\hline \hline \multicolumn{1}{c|}{ Country } & Year & $\begin{array}{c}\text { Researchers per million } \\
\text { inhabitants }\end{array}$ \\
\hline Japan & 2000 & 5,104 \\
\hline United States of America & 1999 & 4,526 \\
\hline Russian Federation & 2000 & 3,479 \\
\hline Germany & 2000 & 3,137 \\
\hline United Kingdom & 1998 & 2,691 \\
\hline South Korea & 2000 & 2,305 \\
\hline China & 2000 & 550 \\
\hline Brazil & 2000 & 352 \\
\hline Mexico & 1999 & 227 \\
\hline South Africa & 2002 & 192 \\
\hline India & 1998 & 120 \\
\hline \hline
\end{tabular}

Table 2 shows a wide gap between industrialized countries and developing countries, while South Korea tends to catch up with industrialized countries. The latter clearly benefit from at least four times more staff to carry out research than developing countries. Their capacity to innovate towards climate-friendly technologies is therefore enhanced.

\subsection{Public attitudes and awareness}

Public attitudes and awareness are hard to pin down, but clearly important in shaping mitigative capacity. Very generally, a culture of compliance enhances regulatory effectiveness, while a society with a more internatioanl orientation is more likely to take mitigative action than an isolated one. Attitudes to climate change can range from treating it as a serious problem requiring action, to perceiving it as a threat to be avoided or denied. Institutions which are important are a free press, and civil society organisations.

Escalating public concern and awareness about the climate change issue is closely linked to the influence, effectiveness, and agenda of national media. For instance, it was not until the Warning of a Threatening Climate Catastrophe, published by the Energy Working Group of the German Physical Society in 1985, that the climate change issue was transformed from a purely research agenda into a national political agenda (Cavender-Bares et al. 2001). Press coverage of this report presented the public with scenes of environmental disasters resulting from climate change, fundamentally changing the framing of the issue. As a result, extensive reductions in greenhouse gas emissions were recommended, and the West German cabinet agreed to a 25$30 \%$ carbon dioxide reduction by 2005 (Cavender-Bares et al. 2001). Although attention to the issue was declining by 1992, municipalities began to set their own reduction targets, and implement concrete measures by which to reach them (Cavender-Bares et al. 2001). 
Similar trends are present in Mexico, where climate change became an issue of considerable public and government concern in the late 1980s and early 1990s. Public awareness of the issue grew following a severe drought in 1989, which coincided with scientific claims about global warming from the United States (Liverman \& O'Brien 2001). As a result, president Carlos Salinas (1988-1994) committed to planting 32 million trees, and in 1992, the Federal Electricity Commission put forward $\$ 10$ million to install low-energy, high-efficiency light bulbs in the cities of Monterey and Guadalajara (Liverman \& O'Brien 2001).

Public awareness and attitudes about climate change may also be influenced by factors other than traditional forms of news media. In the United States, for instance, the Hollywood movie The Day After Tomorrow, which depicted catastrophic events following the shut-down of the North Atlantic thermo-haline circulation system, substantially influenced the attitudes of a majority of the $10 \%$ of Americans who viewed the movie (Liverman \& O'Brien 2001). These movie-goers were considerably more likely than those who did not attend the movie to carry out mitigative action in response to climate change, and to favourably consider information provided by scientists and environmental groups regarding the climate change risk (Liverman \& O'Brien 2001). Although the effect of the movie on the public at a national scale was insignificant, the influence of popular forms of mass entertainment on public attitudes, and thus on regulatory effectiveness and mitigative capacity, should not be underestimated.

Broader public awareness is a factor that may be hard to quantify precisely, but is nonetheless powerful in translating mitigative capacity into mitigation. The educational base and regulatory effectiveness described above are important in shaping mitigative capacity. Technological factors, considered in the following section, operate in this institutional context.

\section{Technological factors}

Technology also contributes to mitigative capacity in various respects (Blanchard 2005). Current technologies used in countries emit more or less GHG per unit of output, therefore providing more or less ability to reduce emissions. A country's capacity to absorb climatefriendly technologies already in use in other countries or develop new-to-the world technologies also plays a role in shaping mitigative capacity.

In this respect, the number of researchers per million inhabitants has already been suggested as a quantitative indicator (section 4.2). Nevertheless, access to infrastructures such as power utilities and information and communication (IC) devices is also essential in the technological development of a country (UN Millennium Project 2004). International data on the access to electricity does not exist. Electricity consumption may be used as a proxy for developing countries (not for industrialized countries where the access rate is close to $100 \%$ ). The number of (mainline and cellular) telephones per 1000 people and the number of Internet users per 1000 people are indicators of the access to IC technologies. 
Table 3: Electricity consumption, number of telephones, Internet users of selected countries Data source : Millennium Project (2004)

\begin{tabular}{|c|c|c|c|}
\hline Country & $\begin{array}{l}\text { Electricity consumption } \\
\text { (kWh/cap), } 2000\end{array}$ & $\begin{array}{c}\text { Telephones per } 1000 \\
\text { people, } 2001\end{array}$ & $\begin{array}{l}\text { Internet users per } \\
1000 \text { people, } 2001\end{array}$ \\
\hline United States of America & 12331 & 1118 & 501 \\
\hline Japan & 7628 & 1174 & 384 \\
\hline Germany & 5963 & 1317 & 374 \\
\hline South Korea & 5607 & 1106 & 521 \\
\hline United Kingdom & 5601 & 1358 & 330 \\
\hline Russian Federation & 4181 & 296 & 29 \\
\hline South Africa & 3745 & 353 & 65 \\
\hline Brazil & 1878 & 385 & 47 \\
\hline Mexico & 1655 & 354 & 36 \\
\hline China & 827 & 248 & 26 \\
\hline India & 355 & 44 & 7 \\
\hline
\end{tabular}

Table 3 shows a gap between industrialized countries and developing countries: access to infrastructures is much higher in the former, suggesting a higher mitigative capacity. South Korea stands at the level of industrialized countries for all indicators, while Russia shows low access rates to IC technologies suggesting a lower mitigative capacity than other industrialized countries.

The capacity of a country to absorb climate-friendly technology or develop new-to-the world technologies influences its mitigative capacity. How much technological capacity gets turned into mitigation is part of the consideration in the following section. More broadly, we address the translation of the ability to reduce GHG emissions into action to mitigate.

\section{From mitigative capacity to mitigation}

How does mitigative capacity get translated into actual mitigation? The process appears to have several steps. We noted that at a general level, all response capacity is rooted in the same substrate - the development path of a country. This general capacity can be turned into specific forms of mitigative capacity, for example an energy efficiency agency. Depending on the flexibility of institutions, capacity might be reversible, i.e. even if it was designed initially for mitigative capacity, it might be transferable to adaptive capacity. There is a small set of actions which achieve both mitigaton and adaptation, but others that are specific to one response.

Mitigative capacity is a necessary, but not sufficient, condition for mitigative action. Capacity is based on the objective factors such as economic factors, institutions and technology. This concept, however, does not speak to whether or not nations will translate capacity into action. A variety of barriers exist to the effective translation of capacity into mitigative action. Abatement costs and political willingness, for instance, may play some role in determining whether or not capacity is turned into action in response to the climate change risk. These examples of barriers to mitigation are examined in more detail below.

The discussion of abatement cost (section 3.2) showed that it is a barrier that might prevent high mitigative capacity (in higher-income countries) from being translated into actual mitigation. Taking a national perspective, it is the GDP (or income) that gives capacity to mitigate. Higher abatement cost means that that financial capacity will be translated into less mitigation. But a country's ability to reduce emissions is not limited by the cost, but rather is only limited by the fact that countries have budget constraints. 
Comparing two countries with the same limited budget, one (e.g Japan) with a higher abatement cost is not able to mitigate as much as one with a lower abatement cost (e.g the US). It cannot turn its limited mitigative capacity into as much mitigation. In relative terms, Japan's ability to reduce GHG emissions is lower than that of the US. High abatement cost is a barrier to turning mitigative capacity into actual mitigation.

Another potential barrier to mitigation is political willingness. Political willingness is not itself a determinant of mitigative capacity. Rather, political willingness is itself shaped by factors that also determine mitigative capacity. For example, if a country faces high levels of poverty, then the political willingness to address GHG emissions will probably be low. Thus, the preceding analysis on mitigative capacity can help explain why political willingness is low in some instances. Different political cultures and styles - anticipatory or reactive; consensus-based or impositional (Richardson \& Watts 1985) - influence the capacity to act at national and local levels. Political willingness becomes a barrier in translating mitigative capacity into actual mitigation.

However, there are also other factors that shape political willingness that are independent from considerations of mitigative capacity and other national circumstances. Those factors include the personal perceptions, preferences, and judgments of decision-makers that are presently in power, the results of elections, etc. For example, a very narrow victory by one candidate can have a very large influence on political willingness, and therefore actual mitigation action. Various factors may suggest mitigative capacity and mitigation opportunities exist, but they remain unexploited. A good example is the United States

The response of the United States to global environmental risks, for instance, is often characterized by a multiplicity of positions, all lacking ultimate authority. This results from the design of American political institutions, which are intended to prevent any single institution or official from exercising complete authority (Porter \& Vernon 1991). The political style of environmental policy in the US tends to be more confrontational, compared to consensual approaches in several European countries (Lindquist 1980). As such, exceptional latitude is allowed for independent initiatives that are fragmented and overlapping. With respect to the issues of climate change mitigation, the recent position of the Bush administration to avoid commitment to global climate mitigation policy arises not out of a lack of mitigative capacity, but a lack of political will rooted in such issues as perceived threats to sovereignty and protection of certain special interests. Paradoxically, however, it was Bush's rejection of the Kyoto Protocol that, in part, stimulated greater willingness to mitigate climate change for other countries (Grubb 2004).

A factor influencing mitigative capacity at the national level is the ability to conclude international agreements and give them effect in domestic law. International agreements are hard to translate into federal law in the US. Lack of federal action on climate change (beyond voluntary measures and business-as-usual intensity targets) has spurred substantial action at the state and local levels in the United States. However, local action is constrained - for example, states cannot mandate fuel economy standards. Allocation of decision-making authority intersects with political will. If the federal government does not act, local and state governments retain some mitigative capacity, but their ability to translate this into mitigation is limited.

In contrast to the response of the United States government to the problem of global climate change is that of Germany. Despite scientific uncertainty, the climate change issue was pushed onto the German political agenda, leading to substantial mitigative action, with public awareness playing an important role (see above). Germans expect the federal government to take strong action in many spheres, including climate (Richardson \& Watts 1985). This promotes a precautionary and proactive approach to decision-making and allowed a for translation of international agreements into a domestic target (25-30\% cut in $\mathrm{CO}_{2}$ emissions by 2005 (Cavender-Bares et al. 2001)). Political willingness in a particular institutional context allowed mitigative capacity to be turned into goals for actual mitigation. 
Abatement cost and political willingness are two important barriers, but clearly not the only ones. Additional factors that may influence the amount of mitigation undertaken are: the relationship between the expert and lay communities, risk perception, industry-regulator relationships, the power and influence of interest groups, and a nation's historical culture and self-perception (Burch \& Robinson 2005). Further research must be carried out to further investigate the nature of the mitigative capacity/mitigation link, and its connection with components of the underlying development path. For example, perceptions of dread and unfamiliarity may translate into varying, but still rational, characterizations of risk. Sociopolitical variables, such as economic insecurity and environmental justice have also been shown to be related to risk perception (Satterfield et al. 2004). With respect to climate change, differing perceptions of risk may lead to wide variation in adaptation and mitigation. In particular, high levels of perceived risk may lead to the activation of adaptive or mitigative capacity, and the subsequent implementation of effective response policies. Psychological and socio-cultural models of risk perception help to elucidate the human dimensions of climate change adaptation and mitigation, and may assist in the creation of more effective policies in response to climate change.

Mitigative capacity in and of itself is not useful; it needs to be turned into mitigative action. In addition to making a conceptual distinction between mitigative capacity and actual mitigation, we have examined some of the barriers - notably abatement cost and political willingness which might prevent capacity from being realised. In conclusion, we reflect on the overall findings on factors influencing mitigative capacity.

\section{Conclusion}

This article has sought to build on Yohe's seminal piece on mitigative capacity which elaborates 'determinants' of mitigative capacity, also reflected in the IPCC's third assessment. We propose a revised definition, where mitigative capacity is a country's ability to reduce anthropogenic greenhouse gas emissions or enhance natural sinks. This capacity can relate either to reducing emissions through climate policy, or making development more sustainable and avoiding emissions. The conceptual framework links mitigative capacity to sustainable development. All response capacities are seen to be rooted in a country's development path, and making development more sustainable helps avoid emissions.

Our conceptual framework groups the factors influencing mitigative capacity into three main sets: economic factors, institutional ones, and technology. Three economic factors - income, abatement cost and opportunity cost - interact to determine mitigative capacity. A greater ability to pay (income) means a higher mitigative capacity. Abatement cost is found to be an important factor in translating capacity into actual mitigation. We show how these parameters vary across countries. Institutional factors that promote mitigative capacity include the effectiveness of government regulation, clear market rules, a skilled work force and public awareness. The flexibility of institutions, we argued, will influence the extent to which they can apply a capacity intended for one use (mitigation) to another (adaptation). Some capacities, notably financial, may be more divisible than others. It is in the translation of mitigative capacity into mitigation that capacities become more specific. Technology is a critical mitigative capacity, including the ability to absorb existing climate-friendly technologies or to develop innovative ones.

Mitigative capacity is a necessary, but not sufficient, condition for mitigative action. Capacity is based on the objective factors such as resource availability, social capital, and the presence of technological options. Mitigative capacity explains how much countries could mitigate, not (by itself) how much they in fact mitigate. We considered barriers, such as high abatement cost or lack of political willingness, that prevent mitigative capacity from being translated into mitigation. An important further analytical step will be to examine how mitigative capacity can be turned into actual mitigation. 


\section{References}

Azar, C \& Schneider, S H 2002. Are the economic costs of stabilising the atmosphere prohibitive? Ecological Economics 42: 73-80.

Banuri, T \& Weyant, J P 2001. Setting the stage: Climate change and sustainable development. Climate Change 2001: Mitigation: Contribution of WG III to the Third Assessment Report of the IPCC. Intergovernmental Panel on Climate Change, Cambridge University Press: 74-114.

Baumert, K, Blanchard, O, Llosa, S \& Perkaus, J F (Eds) 2002. Building on the Kyoto Protocol: Options for protecting the climate. Washington DC, World Resources Institute. http://climate.wri.org/pubs pdf.cfm?PubID=3762.

Blanchard, O 2005. Technological capacity to protect the climate: conceptual approach and tentative indicators. Report to WRI. Washington, World Resources Institute.

Bodansky, D, Chou, S \& Jorge-Tresolini, C 2004. International climate efforts beyond 2012. Arlington, Pew Center on Global Climate Change. www.pewclimate.org.

Burch, S \& Robinson, J 2005. Beyond capacity: A framework for explaining the gap between mitigative capacity and action in response to global climate change. Paper presented at the 6th Open Meeting of the Human Dimensions of Global Environmental Change Research Community, October 13, Bonn.

Cavender-Bares, J, Jager, J \& Ell, R 2001. Developing a precautionary approach: Global environmental risk management in Germany. T S L Group (Ed). Learning to Manage Global Environmental Risks: A Comparative History of Social Responses to Climate Change, Ozone Depletion, and Acid Rain. Volume 1. Cambridge, Massachusetts Institute of Technology Press.

Davidson, O 2002. Sustainable energy and climate change: African perspectives. O Davidson and D Sparks (Eds). Developing energy solutions for climate change: South African research at EDRC, Energy \& Development Research Centre, University of Cape Town: 145-152.

De Canio, S J, Howarth, R B, Sanstad, A H, Schneider, S H \& Thompson, S L 2000. New directions in the economics and integrated assessment of global climate change. Arlington, Pew Center on Global Climate Change. October 2000.

Grubb, M 2004. Kyoto and the future of international climate responses: From here to where? International Review for Environmental Strategies 5 (1): 15-38.

Gupta, S \& Bhandari, P M 1999. An effective allocation criterion for $\mathrm{CO}_{2}$ emissions. Energy Policy (27): 727-736.

Halsnaes, K, Callaway, J M \& Meyer, H J 1998. Economics of greenhouse gas limitations: Methodological guidelines. Roskilde, Denmark, UNEP Collaborating Centre on Energy and Environment.

Heller, T C \& Shukla, P R 2003. Development and climate: Engaging developing countries. Arlington, Pew Center on Global Climate Change.

Höhne, N, Phylipsen, D, Ullrich, S \& Blok, K 2004. Options for the second commitment period of the Kyoto Protocol. Berlin, Federal Environmental Agency (Umweltbundesamt).

Hourcade, J-C \& Robinson, J 1996. Mitigating factors: assessing the costs of reducing GHG emissions. Energy Policy 24 (10/11): 863-873.

IPCC (Intergovernmental Panel on Climate Change) 2001a. Climate change 2001: Synthesis report. Geneva.

IPCC (Intergovernmental Panel on Climate Change) 2001b. Climate Change 2001: Mitigation. Contribution of WG III to the Third Assessment Report of the IPCC. Cambridge, Cambridge University Press for Intergovernmental Panel on Climate Change.

IPCC (Intergovernmental Panel on Climate Change) 2001c. Climate Change 2001: Impacts, adaptation and vulnerability. Contribution of Working Group II to the Third Assessment Report. Cambridge, Cambridge University Press for Intergovernmental Panel on Climate Change.

Lindquist, L 1980. The hare and the tortoise: clean air policies in the United States and Sweden. Ann Arbor, University of Michigan Press.

Liverman, D \& O'Brien, K 2001. Southern skies: The perception and management of global environmental risks in Mexico. T S L Group (Ed). Learning to manage global environmental risks: A comparative history of social responses to climate change, ozone depletion and acid rain. Cambridge, Massachusetts Institute of Technology.

Munasinghe, M \& Swart, R 2005. Primer on climate change and sustainable development: Facts, policy analysis and applications. Cambridge, Cambridge University Press.

Nordhaus, W D 1993. Rolling the 'DICE': An optimal transition path for controlling greenhouse gases. Resource and Energy Economics 15: 27-50.

Norgaard, R B 1994. Development betrayed: The end of progress and a co-evolutionary revisioning of the future. London, Routledge.

Pan, J 2002. Understanding human development potentials and demands for greenhouse gas emissions: with empirical analysis using time series and cross-sectional data. Beijing, Chinese Academy of Social Sciences. 
Porter, R B \& Vernon, R 1991. Foreign Economic Policy-Making in the United States. Cambridge, Center for Business and Government, John F. Kennedy School of Government, Harvard University.

Richardson, J \& Watts, N 1985. National policy styles and the environment: Britain and West Germany compared. Berlin, Wissenschaftszentrum.

Robinson, J, Bradley, M, Busby, P, Connor, D, Murray, A, Sampson, B \& Soper, W forthcoming. Climate change and sustainable development: Realizing the opportunity. Ambio.

Satterfield, T, Mertz, C \& Slovic, P 2004. Discrimination, vulnerability, and justice in the face of risk. Risk Analysis 24 (1): $115-129$.

Shukla, P R, Tudela, F, Davidson, O, Mwakasonda, S, Spalding-Fecher, R, Winkler, H, Mukheibir, P, Alpan-Atamer, S, Chandler, W, J.Secrest, T, Logan, J, Schaeffer, R, Szklo, A S, Schuler, M E, Dadi, Z, Kejun, Z, Yuezhong, Z \& Huaqing, X 2002. Climate change mitigation in developing countries: Brazil, China, India, Mexico, South Africa, and Turkey. Washington DC, Pew Center on Global Climate Change. October.

Swart, R, Robinson, J \& Cohen, S 2003. Climate change and sustainable development: expanding the options. Climate Policy 3 (Supplement 1): S19-S40.

UN Millennium Project 2004. Interim Report of Task Force 10 on science, technology and Innovation. New York, United Nations Development Programme.

UNESCO 2005. Web-site. http://www.uis.unesco.org/TEMPLATE/html/Exceltables/science/R\&DTables02052005.xls.

UNFCCC (United Nations Framework Convention on Climate Change) 1997. Kyoto Protocol to the United Nations Framework Convention on Climate Change. Bonn, UNFCCC Secretariat.

UNFCCC 1992. United Nations Framework Convention on Climate Change. New York, United Nations. http://unfccc.int/resource/conv/index.html.

Winkler, H, Davidson, O \& Mwakasonda, S 2005. Developing institutions for the Clean Development Mechanism: African perspectives. Climate Policy 5: 209-220.

Winkler, H, Spalding-Fecher, R, Mwakasonda, S \& Davidson, O 2002. Sustainable development policies and measures: starting from development to tackle climate change. $\mathrm{K}$ Baumert, O Blanchard, S Llosa and J F Perkaus (Eds). Building on the Kyoto Protocol: Options for protecting the climate. Washington DC, World Resources Institute: 61-87.

WRI (World Resources Institute) 2003. Climate Analysis Indicators Tool (CAIT). Washington DC. www.wri.org.

WRI (World Resources Institute) 2005. Climate Analysis Indicators Tool (CAIT), version 3.0. Washington DC. http://cait.wri.org/.

Yohe, G 2001. Mitigative capacity - the mirror image of adaptive capacity on the emissions side: An editorial. Climatic Change 49: 247-262. 